\title{
THE RESPONSIBILITIES OF ENGINEERS
}

\author{
A Thesis \\ by \\ JUSTIN DOUGLAS SMITH
}

\begin{abstract}
Submitted to the Office of Graduate Studies of
Texas A\&M University

in partial fulfillment of the requirements for the degree of
\end{abstract}

\section{MASTER OF SCIENCE}

\begin{abstract}
Approved by:
Co-Chairs of Committee, Paolo Gardoni Luciana Barroso

Committee Member, Colleen Murphy

Head of Department, John Niedzwecki
\end{abstract}

December 2012

Major Subject: Civil Engineering

Copyright 2012 Justin Douglas Smith 


\begin{abstract}
Knowledge of the responsibilities of engineers is key to answering ethical questions about the work of engineers, because the decisions made by engineers often have ethical dimensions and implications. Engineers develop and implement technologies that influence and shape the way we live, at times in manners unanticipated by those who develop such technologies. To be able to answer important ethical questions, it is essential first to define what the responsibilities of engineers are.
\end{abstract}

This paper defines the responsibilities of engineers by considering what constitutes the nature of engineering as a particular form of activity. Specifically, this paper focuses on the responsibilities of engineers qua engineers, where that refers to the duties acquired in virtue of being a member of a group. In order to answer this question, this paper examines the practice of engineering, drawing on the idea of practices developed by philosopher Alasdair MacIntyre and showing how the elements of a practice are important for finding and justifying the responsibilities of engineers.

To demonstrate the contribution that knowledge of the responsibilities of engineers makes to engineering ethics, a case study is discussed at the end of the paper which deals with ethical questions in the discipline of structural engineering. The circumstances surrounding the failure of the Sleipner A platform off the coast of Norway in 1991 will be discussed to demonstrate how the responsibilities of engineers can be derived from knowledge of the nature of engineering and its context. 


\section{DEDICATION}

This thesis is dedicated to the memory of Donavan Pennington. 


\section{ACKNOWLEDGEMENTS}

I would like to thank my committee co-chairs, Dr. Paolo Gardoni and Dr. Luciana Barroso and my committee member, Dr. Colleen Murphy, for their enthusiasm, empathy, and guidance throughout the course of this research.

I also would like to thank Dr. Stephen Caffey, Assistant Professor in the Department of Architecture for being a friend, confidant, and source of intellectual stimulation during the course of my studies at the university. A debt of gratitude is owed to my friends in Houston, particularly the members of First Light Group and the staff at Insight Structures Inc. I also owe tremendous thanks to my parents, JD and Evelyn Smith, who are both graduates of Texas A\&M University. It is an honor to carry on the family tradition.

Finally, a sincere and enduring debt of gratitude is owed to Julie Brent, without whom this thesis would not have been possible. 


\section{TABLE OF CONTENTS}

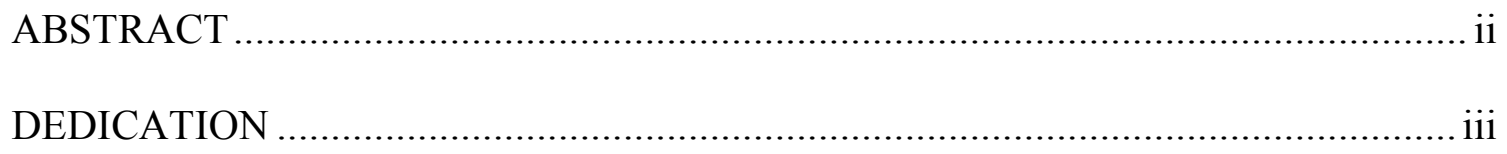

ACKNOWLEDGEMENTS ..................................................................... iv

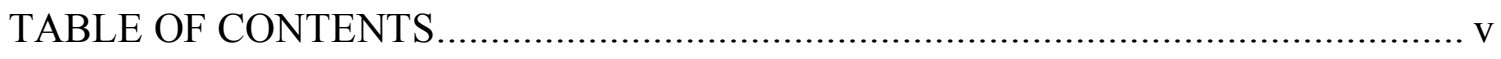

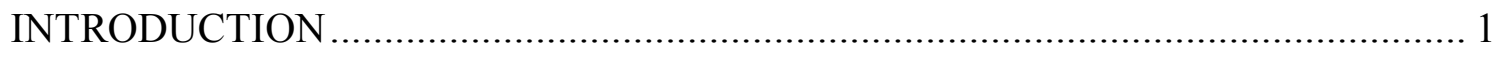

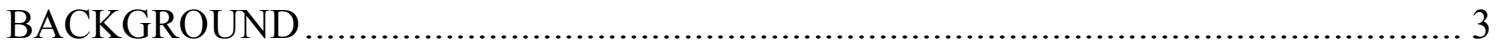

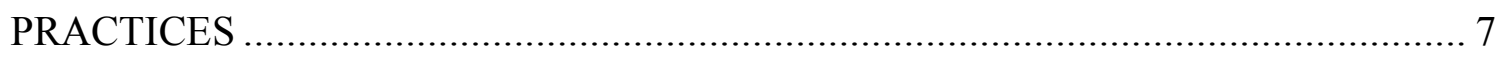

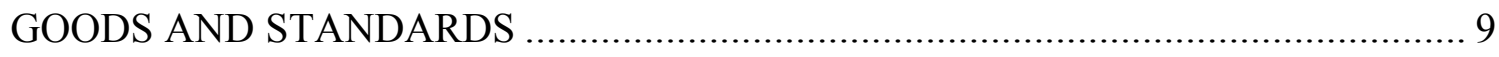

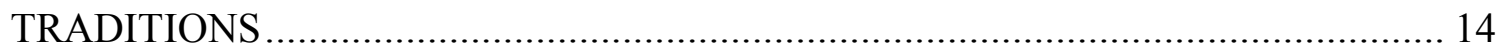

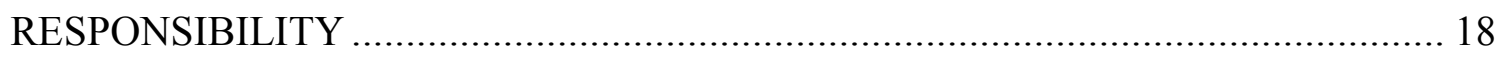

ENGINEERING AS PRACTICE................................................................. 21

THE SLEIPNER A CONDEEP PLATFORM ACCIDENT .................................... 29

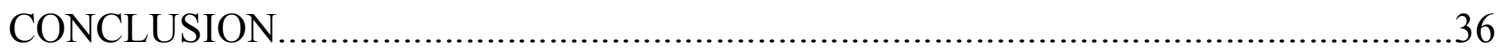

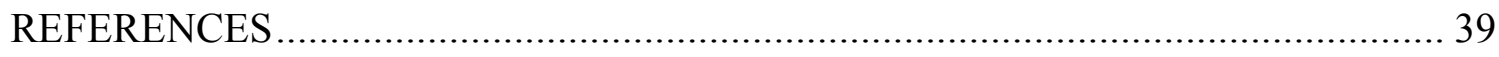




\section{INTRODUCTION}

Knowledge of the responsibilities of engineers is key to answering ethical questions about the work of engineers. The decisions made by engineers often have ethical dimensions and implications. Engineers develop and implement technologies that influence and shape the way we live, at times in manners unanticipated by those who develop such technologies. Engineering projects also have an increasing tendency to influence large populations. One way that engineers impact society is by maintaining roles in industry and academia which influence public policy (Layton 1971; Mead 1980; Unger 1994; Badaracco Jr. 1995; Nissenbaum 2002; Roger A. Pielke 2007). Due to the exportation and out-sourcing of technological labor and expertise via globalization, there is unprecedented demand in less industrialized countries for engineers with advanced degrees, and for Western science and engineering education programs. Finally, because engineering ethics is a more recent field of knowledge than the ethics of other organized professions, much remains to debate about the nature of engineering and the responsibilities of engineers. These circumstances carry unique ethical challenges. To be able to answer important ethical questions, it is essential first to define what the responsibilities of engineers are.

Current literature recognizes a number of challenges in defining engineers' responsibilities. Deborah Johnson claims that applied moral theories have yet to reveal what social responsibilities engineers have specifically as engineers (Johnson 1992). Similarly, other authors have recognized various problems in the use of maxims from moral philosophy as guides to defining the responsibilities of engineers (Busby and Coeckelbergh 2003; Bowen 2010). Neelke Doorn and Michael Davis have introduced philosophical models of responsibility to engineering ethics, however they are not intended to identify what engineers' responsibilities are (Doorn 2009; Davis 2010) Instead they describe the practical benefits that come from a better understanding of responsibility. Finally, it is also common to emphasize those responsibilities which are 
expected of professionals in general when discussing the responsibilities of engineers. This is how Charles Fleddermann arrives at the responsibilities to protect client confidentiality and to avoid conflicts of interest (Fleddermann 1999). All of these approaches avoid the question of what responsibilities engineers have qua engineers.

This paper defines the responsibilities of engineers by considering what constitutes the nature of engineering as a particular form of activity. Specifically, this paper starts by asking this question: How can the responsibilities of engineers be explained by what we know of engineering work and the circumstances in which it takes place? In order to answer this question, this paper examines the practice of engineering, drawing on the idea of practices developed by philosopher Alasdair MacIntyre and showing how the elements of a practice are important for finding and justifying the responsibilities of engineers. This examination will help to explain how the responsibilities of engineers can be recognized and what those responsibilities are. To demonstrate the contribution that knowledge of the responsibilities of engineers makes to engineering ethics, a case study is discussed at the end of the paper which deals with ethical questions in the discipline of structural engineering.

After this introduction, this paper provides a more detailed look at how responsibility has been discussed in the field of engineering ethics. Then this paper lays out the concepts Alasdair MacIntyre has used to explain the ethics of specific practices, also explaining how these concepts apply to engineering. Next, this paper will provide an critical analysis of papers in the field of engineering ethics which apply MacIntyre's work. Following these points will be a section proposing what engineers might be responsible for and how this is justified. Finally, circumstances surrounding the failure of the Sleipner A platform off the coast of Norway in 1991 will be discussed to demonstrate how the responsibilities of engineers can be derived from knowledge of the nature of engineering and its context. 


\section{BACKGROUND}

This section provides a background on how responsibility has been discussed in engineering ethics and the definition of responsibility used in this paper. First, we summarize the literature on engineers' responsibilities. Then, we provide the definition of responsibility adopted in this paper and discuss how this definition contributes to the goal of identifying the responsibilities of engineers.

Responsibility itself is a complex subject and needs to be defined by any paper taking it to be its subject matter. In engineering ethics and in moral philosophy, the term responsibility can have varying meanings and qualifications. For example, some speak of responsibility as a form of accountability, while others link it with conditions for blameworthiness (Fischer and Tognazzini 2011; Smith 2007; Doorn and NihlénFahlquist 2010; Doorn 2009; Watson 1996; Davis 2010). The requirements to prove an individual is responsible and what they can actually be responsible for are also variable. Each usage results in a different account of engineers' responsibilities.

In specifying the responsibilities of engineers and evaluating engineering conduct, different accounts also arise from the application of differing moral philosophies such as deontology, consequentialism, and virtue ethics to engineering problems. The differences between moral philosophies are openly acknowledged by a number of authors. Busby and Coeckelbergh, for instance, note that there is a common perception that engineers make ethical decisions based upon utilitarian principles while the public tends to form their expectations of engineers along deontological lines (Busby and Coeckelbergh 2003). From this perspective, engineers see themselves as largely responsible for reducing quantifiable levels of risk and harm, while the public thinks that engineers are responsible for fulfilling strictly prescribed duties to society. Richard Bowen argues that the theories of consequentialism, contractualism, and deontology have specific disadvantages when instituted in the field of engineering ethics (Bowen 
2010). Bowen claims that consequentialism contains no provision for justice, contractualism limits ethical aspiration, and deontology's dense philosophical foundation is too impenetrable for engineers.

In the contemporary engineering ethics literature, authors often contrast social and technical responsibilities, and there is disagreement about which kind of responsibility should be prioritized. Carl Mitcham notes that American engineers in the 1960's and 1970's criticized the technocratic movement of previous decades for its lack of social consciousness (Mitcham 1994). Mitcham's observation highlights the difference between thinking that engineers are responsible for technological advancement only, as opposed to being responsible for the consequences that technology has for people. The difference between technical and social responsibilities is also an issue in readings such as the work of Bowen (Bowen 2010 p. 135-6). Bowen points to two problems with an overemphasis on technical progress. First, he claims that much energy, including economic resources and time, is spent on the development of technologies, such as weaponry, that he argues do not benefit society. Second, Bowen points out that even established engineering technologies, such as water sanitation, are not available to everyone who needs them. Bowen concludes that engineers should work to correct the imbalance between technological ability and social need by prioritizing people. However, it is unclear whether the responsibility should be one belonging directly to engineers or if society should be responsible for resource allocation and support so that engineers can work toward such priorities. Also, it is hardly explicit in any paper that takes up these differences what exactly differentiates technical responsibilities from social responsibilities.

There is also much debate about the extent to which engineers have the responsibility to contribute to the betterment of society. There are those authors who base the responsibility to benefit society upon aspirational ethics, appeals to codes of engineering ethics calling engineers to "hold paramount the safety, health, and welfare of the public," 
or duties of professionalism (Nichols and Weldon 1997; Bowen 2010; Davis 1997; Harris 2008; Pritchard 1998, 2001; NSPE 2007). There is also a contrary, though less popular, view. From this perspective, James Stieb claims that the responsibilities of engineers ought to be limited to the realm of professional competence, committing engineers only to the responsibility of avoiding harm to others while absolving engineers of the commonly accepted responsibility to benefit humanity (Stieb 2011). As with the difference between the technical and social responsibilities, this disagreement between an obligation to avoid harm or to benefit society depends upon where one chooses to draw the line between harmless and beneficial technologies.

By contrast with the above approaches, this paper focuses on the responsibilities of engineers qua engineers, where that refers to the duties acquired in virtue of being a member of a group. This definition captures how a number of theorists think of ethics in general. Carl Skooglund states that ethics concerns "how we agree to relate to one another (in Nichols and Weldon 1997). Michael Davis refers to ethics as "those (morally permissible) standards of conduct (rules, principles, or ideals) that apply to members of a group simply because they are members of that group (Davis 2011)." These theorists capture what we are concerned with: the responsibilities that a person has specifically as a member of a discipline or group. What we mean by the responsibilities of engineers will have to do with how engineers adhere to the standards and methods set for engineering by society and engineers. This approach allows us to specify responsibilities of engineers prior to evaluating whether those responsibilities are utilitarian, deontological, social, technical, aspirational, or otherwise. It is also neutral at the outset between whether this should include technical and/or social duties.

The claims that this paper makes regarding the responsibilities of engineers will only be as good as the account that we can make of engineers and the way they work. It is important to underscore the act of making an account of some organized activity for two reasons. If two criticisms of engineering are compared, the one that will be most credible 
is the one that makes the most insightful account of engineering practice. The second important reason follows the first. Understanding the relationship between an activity and credible responsibility ascriptions will help explain the importance of three concepts used by Alasdair MacIntyre. These are the concepts of tradition, narrativity, and intelligibility. The main point we are making here is that an account of engineering is required in order to formulate what can be expected from engineers. The strength of such account directly influences the legitimacy of responsibility ascriptions. 


\section{PRACTICES}

Before using the philosophy of Alasdair MacIntyre to clarify the responsibilities of engineers, concepts from MacIntyre's philosophy need to be defined. In this section, we focus on practices, before going on to consider goods, standards of excellence, and traditions in the next sections.

MacIntyre defines a practice as:

...any coherent and complex form of socially established cooperative human activity through which goods internal to that form of activity are realized in the course of trying to achieve those standards of excellence which are appropriate to, and partially definitive of, that form of activity, with the result that human powers to achieve excellence, and human conceptions of the ends and goods involved, are systematically extended (MacIntyre 1984a p. 187).

In other words, a practice is a socially organized activity that exists by means of relationships between society members. There are goods that practitioners receive as a result of attempting to achieve excellence in their practice. These goods are internal because they can only be achieved by engaging in the practice. Counter to these, MacIntyre notes the existence of external goods such as money and fame which might come from a practice but can be earned in a number of other ways. As practitioners work to achieve and maintain those standards which constitute excellence for the their practice, not only do they obtain certain goods, but the practice evolves. The achievements and goals of the practice are refined. Adding numbers is not a practice because it is not socially established, the act of doing so has no history, and the act has no changing conceptions of excellence. Mathematics is however a practice because the activity has its own standards of excellence which mathematicians regularly attempt to 
achieve and improve upon. Mathematics also has a lively social history marked by the sharing and building up of ideas in university math departments, in journals, and in research. All of this activity amounts to a systematic extension of what mathematics is useful for and the goods that mathematicians gain from doing mathematics.

MacIntyre gives a fundamental role to the concept of practices within his moral philosophy because of their predominance in human civilization around the world and throughout history. All places and times that have had their own societies have had their own practices. By making practices central to moral philosophy, MacIntyre is making a case for universal claims that do not contradict what might be morally appropriate for one place in time but not another. 


\section{GOODS AND STANDARDS}

MacIntyre claims that practices are partially defined by their standards of excellence, and it is apparent from his definition that practices are closely linked to various types of goods as well. By taking a closer look at these concepts, we are building upon the basic concept of a practice as MacIntyre does. Most importantly we are establishing some guides to determining what practitioners are responsible for. In this section, we define the concepts of internal goods, external goods, and standards of excellence and put them into the context of an example taken from MacIntyre.

Internal goods are those goods which by definition are obtained by practitioners as they attempt to achieve the standards of excellence in their practice (MacIntyre 1984a pp. 188-90). They are specific to a practice and can only be had as a result of participating in that practice (MacIntyre 1984a p. 188). The fact that internal goods cannot be achieved without engaging in a practice means that they are best understood and explained by those with experience in the practice (MacIntyre 1984app. 188-89). Most importantly, internal goods serve as reasons for "trying to excel in whatever way the [practice] demands (MacIntyre 1984a p. 188).” Participating in order to excel and earn the internal goods is the moral requirement of MacIntyre's concept of practices.

External goods are those goods which can be earned in variable ways and do not need to be associated with any particular practice to be understood. These goods are typically money, status, and prestige (MacIntyre 1984a p. 188). Participation in a practice in order to obtain solely external goods is not a means for enriching society, furthering the practice or finding the good life for one's self. In order to see this better, we can ask ourselves what it would be like to live in a society where external goods prevail. This would be a society fraught with inequality and competitiveness, because external goods are limited in supply (MacIntyre 1984a p. 196). The more one person has, the less there are for others (MacIntyre 1984a pp. 190-1). It follows then that placing the external 
goods as the sole impetus for engaging in a practice can have negative consequences such as inequality or, as Dennis Randolph notes, economic instability and waste (Randolph 1992). This idea reinforces the fact that pursuing the internal goods and excellence in a practice is to participate for the correct reasons.

Standards of excellence are authoritative ideals by which the work of practitioners are judged (MacIntyre 1984a p. 190). They must be accepted as authoritative if one is to work towards achieving and improving them. MacIntyre says that "we cannot be initiated into a practice without accepting the authority of the best standards realized so far (MacIntyre 1984a p. 190)" It is important to note here that MacIntyre is referring to participation in a practice, not just engaging in a random act or skill which does not qualify as a practice. Actions such as skills may not require the acceptance of prerequisite standards of excellence because they are not sustained by a process of extending any particular set of ends, goods, and standards.

Both internal goods and standards of excellence, as elements which define a practice, are perpetually open to revision and debate as new ideals are established (MacIntyre 1984a pp. 190, 221-2). One way that we suggest this can be recognized is when the practice is faced with a set of problems. Problems in the practice invariably arise, and it is the activity of practitioners to solve those problems. In doing so, they find new means, set new standards and define new ends for the practice (MacIntyre 1984b p. 36-7; 1984a p. 190). This is precisely how practices sustain themselves and forge histories. It is the reason there is a difference between what was accepted as good in the past and what is good today. However, the standards of excellence and internal goods of some practice in a particular time and place are necessary for defining that era of practice.

The standard example MacIntyre provides to explain the relationship between goods, a practice, and excellence is that of a young chess player (MacIntyre 1984a; Bowen 2010; van der Burg and van Gorp 2005). However, for purposes of understanding the goods 
and standards of excellence of a profession, a more appropriate example to consider is MacIntyre's example of $18^{\text {th }}$ century European portraiture.

MacIntyre explains how one can understand the standards of excellence that defined this genre of painting. In earlier centuries, two standards had defined two prior genres from which the contemporary genre evolved. The first MacIntyre identifies as the painting of religious iconography, particularly depictions of the face of Christ (MacIntyre 1984a p. 189). What mattered in this genre was not how real the subject matter appeared, but the power of the composition to convey an idea or narrative to the viewer. The second genre, realism, came later and was dependent upon the painters' ability to render the faces of people so that portraits relayed in fine detail what their subjects looked like. The painting of iconography involved relaying meaning while realism involved a precise depiction of visual reality. The standard of excellence that defines $18^{\text {th }}$ century European portraiture achieved a symbiosis of the two excellences. Individuals were painted with all of the detail of realism, however they were rendered in such a way as to reveal some underlying truth or commentary about the subject (MacIntyre 1984a p. 189). MacIntyre says that the painters of this genre were able to paint their subjects not just as they appeared to the eye, but as they deserved to be painted. The objective to render reality in such a way as to reveal a greater truth is the standard of excellence which defined $18^{\text {th }}$ century European portraiture.

MacIntyre goes on to propose two internal goods of $18^{\text {th }}$ century European portraiture. First, he posits as the internal good of the practice "excellence in performance by the painters and that of each portrait itself (MacIntyre 1984a p. 189)." The key to understanding this statement is to grasp that MacIntyre means the goods come in the form of accomplishments as one excels beyond current "types and modes of excellence (MacIntyre 1984a p. 189)." Performance means to combine technical precision with the ability to accentuate the character of the subjects of their portraiture. The portraits themselves were internal goods realized not just by the artist but also the "whole 
community who participate in the practice (MacIntyre 1984a p. 190-1)". In trying to meet the standards of excellence governing their practice artists developed the ability to render truth through painting in a way not done before. The progress both in the abilities of the painters and the masterworks they produced are the internal goods of this genre of painting.

Alongside these excellences in performance and products, there is the internal good of living the life of a painter. MacIntyre says, "it is the painter's living out of a greater or lesser part of his or her life as a painter that is the second kind of good internal to painting (MacIntyre 1984a p. 190)." This does not mean that the internal good of being a painter is prestige or social status (MacIntyre 1984a p. 189). Instead, in the process of pursuing excellence in painting, painters are absorbed in their work in such a way that it becomes a part of their identity. MacIntyre's position is that we derive our identity from the roles we occupy, so that finding what is good for us is directly related to the internal good of having a role in a practice.

This example of $18^{\text {th }}$ century European portraiture, shows exactly how a practice is defined by those internal goods and standards of excellence which have evolved from previous goods and standards. This is an important point because the history of a practice is constituted exactly by the process of arguing, revising, and improving that practice's internal goods and standards of excellence (MacIntyre 1984a p. 221-2). This point will be taken up more earnestly in the following section on tradition.

So far, this paper finds that internal goods, participation in practices, and standards of excellence are the foundations of what practitioners should be doing and thus are responsible for. By understanding internal goods and standards of excellence as MacIntyre does, we can make an initial statement about these responsibilities. First, practitioners are responsible for knowing the standards of excellence of their practice. This means knowing them sufficiently so that one can submit to their authority as one 
learns a practice. It also means knowing them as one practices so that they can be followed and improved upon. Perhaps not all practitioners will have the chance or ability to greatly further the standards of excellence of their practice, but all must contribute. This is why knowing them and adhering to them are important, because this course of action does indeed contribute to a collective attempt to progress the practice. Second, practitioners are responsible for engaging in the practice for the right reasons. These reasons are the internal goods of the practice. Based upon what we have learned from MacIntyre so far, we can say that practitioners are responsible for knowing, maintaining, and improving the standards of excellence of a practice. They are also responsible for contributing to the health of the practice by pursuing its internal goods. 


\section{TRADITIONS}

MacIntyre's concept of tradition helps to determine the responsibilities of members of practices, particularly members of professions such as engineering, because such practices have long histories over which present obligations have developed. The concept of tradition encourages us to view these responsibilities from a historical and more broad social perspective. In this section, MacIntyre's definition of the concept of tradition will be defined and examined for the way that it helps us to better define the responsibilities of members of a practice.

Before defining what MacIntyre means by a tradition, it will be helpful to understand how he says a narrative of peoples' circumstances makes their actions intelligible. MacIntyre's philosophy relies heavily on the idea that all human actions take place within larger stories that we tell to ourselves and others in order to make sense of those actions. The example MacIntyre provides involves a person working in a garden (MacIntyre 1984a p. 206). There are many ways that a gardener's actions can be interpreted. One way is to understand that the gardener's intention is to exercise and gardening is one such way to do it. Another is to see that the gardener's intention is to prepare the garden for winter. Another is to see that the gardener is merely trying to please a spouse. All of these different ways of interpreting the actions of the gardener depend upon the gardener's relationship with different social and historical contexts that take the form of narratives. If pleasing the spouse is important there will be a narrative of the gardener's marriage which explains why this is so. The need for exercise will be explained by a different story. Preparing the garden for winter may be important because the history of the gardening on a European farm has shown that this is the best practice of gardening. This is yet another narrative. MacIntyre uses this example to explain how what we do, our behaviors and intentions, rely on the context provided to them by a narrative. The narrative is required in order to make sense of our actions, that is to make them intelligible. 
After establishing narrative as the way of making our actions intelligible, MacIntyre introduces his concept of tradition. MacIntyre defines tradition in the following terms:

A living tradition then is an historically extended, socially embodied argument, and an argument precisely in part about the goods which constitute the tradition. Within a tradition the pursuit of goods extends through generations sometimes through many generations. Hence the individual's search for his or her good is generally and characteristically conducted within a context defined by those traditions of which the individual's life is a part, and this is true both of those goods which are internal to practices and of the goods of a single life (MacIntyre 1984a p. 222).

A tradition is a historically extended process of collectively reasoning what defines the good or goods of a particular social setting. All individuals live their lives and all practices exist within the longer histories of these traditions. What is an internal good today or what an individual finds to define their life as good will be influenced by conceptions of goods which have been previously determined by past members of a practice or other relevant social body.

It is apparent from MacIntyre's definition of traditions, that a tradition can be the history of a practice. In MacIntyre's words, "practices always have histories and that at any given moment what a practice is depends upon a mode of understanding it which has been transmitted often through many generations (MacIntyre 1984a p. 221)." This transmission is part of the narrative of a practice and understanding the present practice by knowing its history is how it becomes intelligible (MacIntyre 1984a p. 222). So, what we know about a practice in the present depends upon what has been transmitted through the practice's history. Therefore, our understanding of a practice depends upon what we know of its history. These are the reasons that looking at the tradition of a practice is important. 
Practices become traditions through their activity of progress and change. Practices, by MacIntyre's definition, involve extending our notions of "excellence and the ends and goods involved". One way that this extension occurs is as a result of a debate amongst practitioners concerning what is best for the practice (MacIntyre 1984a p. 222). This debate over the good for a practice includes the intention to make progress in the areas of excellences, ends and goods. When this debate occurs over time, a tradition is formed. First we noted that a practice is defined by its standards of excellence and its internal goods. Now, we are adding that these aspects of the practice evolve over time by means of the argumentation MacIntyre associates with traditions.

The concept of tradition allows us to make a distinction between goods such as those internal to practices and the good that MacIntyre also frequently refers to. First, there is what MacIntyre refers to as the good of an individual life. This good is whatever answer satisfies the question of how one is to best live one's entire life from beginning to end (MacIntyre 1984a p. 218). Part of this answer comes from asking what constitutes the good life for someone who occupies the same social role (MacIntyre 1984a p. 220). This good is not only defined by those people who share a similar place and time but also those predecessors from which a person inherits a tradition. This means that what defines a good life for those who immediately precede us in our practices sets our "moral starting point (MacIntyre 1984a p. 220)." We learn from their standards of excellence, inherit their responsibilities, and begin our own search for the good from what constituted the good for them.

The inheritance of a conception of good is only a starting point and what follows is a further search for what constitutes a good life in present circumstances. MacIntyre refers to this search as a quest, directly associating the word quest with an attempt to answer the question of what it means to lead a good life (MacIntyre 1984a p. 219). Part of this answer involves seeking the internal goods of practices. However, the answer to this question is not predetermined but includes a measure of unpredictability. This allows for 
the fact that during the course of searching for the good, whether it be the good for an individual or the goods of a practice, conflicts are bound to present themselves. For this thesis it is important to recognize that these troubles appear within practices as problems. As challenges are faced and overcome in the course of living out our lives and practices we arrive at new conceptions of good.

Knowledge of this process contributes to our account of what we ought to do today and what might be possible for the future. First one inherits responsibilities, standards of excellence, and conceptions of both goods and the good from our predecessors so that we have a place to start. This is the fundamental importance of tradition. Then, as one participates in a practice by achieving and advancing its standards of excellence what defines those standards evolves. As a result, the goals and goods of our practices and lives are extended. We propose that this process also includes inheriting problems, solving those problems, and forming new problems which are passed on to future practitioners. MacIntyre makes reference to the role of tradition in this process by saying, "that an adequate sense of tradition manifests itself in a grasp of future possibilities which the past has made to the present (MacIntyre 1984a p. 223)." If it is true that the present state of a practice is embedded in a longer tradition of its development, then we find ourselves in the middle of a narrative as it is being written (MacIntyre 1984a). It follows that if the future is to ever be intelligible, and we have no real reason to think otherwise, then establishing the future good will depend upon how well we structure our present quest for the good today. 


\section{RESPONSIBILITY}

We can derive the responsibilities of practitioners from MacIntyre's philosophy be looking closely at the relationship between the system he has laid out and the question of what one ought to do. In previous sections, this thesis made some initial statements about the responsibility to know, maintain, and advance standards of excellence. It also noted that responsibility today is inherited from past practitioners in a way that does not disregard future responsibilities. In this section, these statements will be organized and expanded upon in light of what MacIntyre says specifically about our duties.

Initially, we said that a practitioner is responsible for three things in relation to the relevant standards of excellence in their practice. The three responsibilities associated with standards of excellence are:

1. Learning the current standards of excellence defining the practice.

2. Maintaining adherence to those standards of excellence as one engages in the practice.

3. Advancing the standards of excellence by identifying and solving problems faced by the practice.

MacIntyre's concept of tradition encourages us to also view responsibility as an obligation that is inherited from past practitioners and passed on in modified form to future practitioners. In the previous section we stated that practitioners do inherit problems, solve them, and formulate new ones to be passed on. This is one way that responsibilities can be derived from the concept tradition. Two relevant responsibilities are:

4. Practitioners are responsible for working on the problems inherited from the past. 
5. Practitioners are responsible for clarifying problems for the present and future.

We also said that practitioners ought to engage in their practice for the right reasons. This statement can be taken as a responsibility because what we ought to do as practitioners translates into our duties. The reason that practitioners should engage in their practice is to achieve and advance the internal goods of the practice. This does not mean that external goods are not important. In MacIntyre's philosophy, external goods are largely managed by institutions which do generally serve in support of practices. So, practices and institutions, as well as internal and external goods, are closely linked. However, the reasons for deciding one course of action over another when acting on behalf of an institution or on behalf of a practice, often conflict. This paper agrees with MacIntyre that the motivation to participate in a practice ought to be to pursue the internal goods. It also agrees that external goods are necessary to the life of institutions and, by extension, practices. The question is how to articulate this point in terms of a responsibility. We formulate such a responsibility by saying:

6. Practitioners are responsible for making decisions in their work based upon the understanding that the quest for external goods and power of institutions must be tempered with an emphasis on the internal goods of practices.

The final responsibility that this paper finds important is derived from the fact that our behaviors and the intentions behind them require a narrative account in order to make sense. Having an accurate account about why a person behaved in a certain way, particularly one that shows them furthering goods and standards of one tradition rather than another, is valuable for those people who must place blame. In other words, the prerequisite for judgment about whether a person is responsible or not needs to reference a narrative of their behavior (MacIntyre 1984a p. 218). However, this idea works in reverse as well, because it is reasonable to expect that an actor be able to provide their own account of their behaviors and intentions (MacIntyre 1984a pp. 209, 217-8). This is 
to say that people should be accountable in the sense that they can put their actions into the context of a narrative that explains why they acted in the way they did. In formal terms the relevant responsibility can be stated as:

7. Practitioners are responsible for maintaining an account of their behavior, decisions, and intentions.

This obligation makes a valuable contribution to the overall framework of responsibility. First, the ability to put actions into narrative explanations of them is an extension of the moral agency required by many philosophers setting prerequisite standards of responsibility and blameworthiness. To make an adequate account of our behaviors in moral terms fulfills the prerequisite because it requires moral competence to do so. If this is to be done in terms of goods and standards, then the practitioners must posses an understanding of the roles goods and standards play in morality and their work. Second, in many areas of life we will be called on by others of authority or victims of harm to explain our behaviors. When the actions of a practice effect others, one can judge from such accounts the intentions of practitioners and more precisely, the transgressions in question. These questions precede decisions as to what level of blame can be administered to practitioners. Third, when a practitioner makes an intelligible account of their actions for other practitioners, this account contributes to the furthering of the practice. This is one way knowledge can be shared within the practice and goods and standards furthered as a result. For these reasons, it is fair to say that people are responsible for maintaining and being prepared to offer, when justified by authority or harm, a narrative account of their actions. 


\section{ENGINEERING AS PRACTICE}

In order to determine the responsibilities of engineers along the lines previously discussed, this paper takes a closer look at what qualifies engineering as a practice and what relevant standards and goods it posseses. It is important to be specific about the particular branch of engineering we are referring to for the same reason MacIntyre singled out $18^{\text {th }}$ century European portraiture in his writing on practices. This reason is that different types of pracitces in different eras are likely to have different histories and standards and thus have different responsiblities. This paper will look at the responsiblities of structural engineers in the past several decades with two objectives in mind. First, how engineering qualifies as a practice will be discussed. Then, several components of the practice of structural engineering will be examined for the way they demonstrate how responsibilities can be derived from practice standards of excellence and internal goods. Though there are many ways a practice such as structural engineering can be discussed in MacIntyre's terms, this paper will focus upon standards of excellence and internal goods because these are directly applicable to the daily pracitce of structural engineering.

To begin, engineering qualifies as a practice according to MacIntyre's definition because it is a cooperative activity defined by standards of excellence which, when pursued, results in internal goods and an extension of the ends involved (Bowen 2010; Martin 2002; van der Burg and van Gorp 2005). Engineering is cooperative and socially established, meaning that the engineering profession exists by means of relationships between engineers who work together to maintain and improve the practice. Imagine just how engineering would appear if what we thought engineering to be was entirely independent of the contributions of people working to improve upon each other's ideas over the course of history. Engineering also has its own clearly defined standards of excellence. When these standards are followed, in an improvement of the ends of 
engineering practice are achieved and extended. These points about engineering in general are also true for the practice of structural engineering specifically.

One immediate source of standards governing the practice of structural engineering are the practice's technical codes. Technical codes serve as guidelines governing structural design in the materials of concrete, wood, and steel. Technical codes specify dimensions and grades of materials, so that safety and performance can be achieved in commonly encountered situations. For instance, technical codes tell us the number of nails required to join two pieces of lumber in prescribed configurations. They also tell us the lightest steel beam available for a particular case of loading so that material is saved and strength is ensured. Concrete codes dictate how much steel reinforcing is necessary to avoid sudden failure of structures or how much concrete coverage should be maintained around reinforcement to ensure longevity. Most often in engineering ethics, emphasis is placed upon the codes of ethical conduct publishing by professional engineering societies. Often quoted are the rules to 'hold paramount the health, safety, and welfare of the public' or 'to protect client confidentiality (NSPE 2007).' Though there is much discussion about these ethical codes in papers on the responsibilities of engineers, this thesis takes lesser discussed, technical codes used in engineering as equally relevant standards for the topic of responsibility. Three reasons this is so are that the technical codes change in sync with evolution of the practice, they are the direct result of daily activities, such as research and design on the part of engineers in cooperation with each other, and they are unique to engineering in a way that the ethical codes are not.

As an example, one can look to the American Institute of Steel Construction's Specification for Structural Steel Buildings (American Institute of Steel Construction. 2010). The specification's preface reveals that this design guide

is the result of the consensus deliberations of a committee of structural engineers with wide experience and high professional standing, representing a wide geographical distribution throughout the United States. The 
committee includes approximately equal numbers of engineers in private practice and code agencies, engineers involved in research and teaching, and engineers employed by steel fabricating and producing companies (American Institute of Steel Construction. 2010 p. 16.1-v).

This work is developed and approved by an identifiable body of structural engineers. It is the result of social cooperation in engineering. The code is "based upon past successful usage, advances in the state of knowledge, and changes in design practice (American Institute of Steel Construction. 2010 p. 16.1-v)." This is precisely how standards should evolve if engineering is a practice according to MacIntyre's definition. The most recent version of the code gives priority to contemporary methods of structural design such as the direct analysis method. This method takes into account second-order loading effects on steel structures making them more efficient, stable, and safe. The direct analysis method is made possible by the widespread use of computer analysis tools, and it represents the current standard of practice in structural engineering within the United States. It is the development, maintenance, refinement, and authority of such codes that qualify them as standards in the terms MacIntyre associates with practices.

So far, we have refrained from using the term excellence to describe technical codes as standards. Perhaps the strongest point that justifies these standards as standards of excellence according to MacIntyre stems from understanding standards of excellence as those standards which have excelled historically (MacIntyre 1984a p. 189). It still could be argued that these authoritative and formal standards serve only as minimum standards. However, as with the AISC Specification, current codes reflect the current state of knowledge and methodologies in the practice. Furthermore, they attempt to strike an ideal balance between a number of design criteria such as safety and efficiency. Consider an instance when a beam is being designed for a building. Though, a different size beam may work, the probabilities used to develop the recommendations contained in the specification ensure a high degree of safety balanced with an attentiveness to efficiency. A stronger beam may offer a greater sense of safety though it would be 
unnecessarily strong. A weaker beam may work some of the time, or for a limited time, or provide strength but result in undesirable deflections and vibrations. The code offers a way to strike the appropriate balance between the two. Thus the term minimal is misleading because we are talking about an outcome involving multiple variables.

There are also ideals in engineering practice upon which technical codes are founded and more importantly serve as guides for circumstances in which the technical codes are insufficient. These ideals are the abstract models of physical phenomenon which engineers develop and use to predict the behavior of their designs. The practical use of scientific or mathematic models to predict the behavior of physical materials is a unique activity and hallmark of engineering. It is what Mitcham refers to as engineering's “"internal' trait of modeling (Mitcham 1994 p. 162)." These models are understood to give the most accurate available prediction of material behavior under prescribed conditions. The most contemporary, accurate, efficient, or appropriate methods of solving an engineering problem depend on the progressive evolution of these models. One example of the progress of such activity in structural engineering, is the transformation from one theory of how to judge the strength of a beam to another. The $17^{\text {th }}$ century produced Galilean rules of thumb directing that beams be loaded along their narrow side (Timoshenko 1983). Then came Hooke's explanation of the relationship between material strength and deformation. In the early $19^{\text {th }}$ century, Navier showed how theories of elasticity could be used to solve indeterminate beam problems. Shortly after, Cauchy developed a mathematically rigorous model of elastic behavior. With the advent of computers in the $20^{\text {th }}$ century, the most modern methods of strength determination in beams have been incorporated into software programs doing finite element calculations.

The previously mentioned standards of excellence in structural engineering exist to aid in the achievement of particular, evolving goals of design and research. In MacIntyre's writings, it is not always easy to make a clear distinction between what is an internal 
good and what he sometimes refers to as the ends of a practice. It could be argued that internal goods are ends realized by practitioners. It could also be argued that internal goods not only benefit practitioners but exist as goods everyone benefits from (Martin 2002). What follows is a discussion of several goals of structural engineering which can be construed as internal goods or ends but regardless, can be related to responsibilities.

There are a number of ideal outcomes which measure the success of a structural engineering project. These goals are plausible candidates for internal goods in the way that the performance and products of painters were in MacIntyre's previous example. In ancient civilizations, early engineers were responsible for ensuring a prescribed result such as building a monument or constructing an irrigation system. This seemed to be the goal regardless of the human cost of construction and experimental, full-scale failures (Wells 2010). As engineering knowledge progressed and the demands of society became more intricate, the outcomes of engineering work have taken on more clearly defined requirements. In the past several centuries, adequate strength and efficiency of geometries and materials have become outcomes more avidly pursued by means of increasingly specialized knowledge. Serviceability and stability are also now requirements of comparable importance. Safety, not only for end users of structured objects but also for people involved in building and manufacture is also an important consideration. In more recent decades, sustainability in structural engineering has become a conscious goal, particularly for those structural engineers involved in areas of structural health monitoring, diagnostics, and rehabilitation. Though some of these ends are more recent additions to the goals of structural engineering than others, the aims of strength, stability, serviceability, safety, and sustainability are ends or goods which contemporary structural engineers adopt for themselves and work to achieve. They are ideals structural engineers are responsible for pursuing. 
The standards of excellence and goals of structural engineering determine what structural engineers are responsible for in the terms laid out by this paper. They can be summarized in the following way:

1. Structural engineers have the responsibility to know and follow current technical codes of structural engineering practice.

2. Structural engineers are responsible for using the best abstract mathematical and scientific models currently available. This requires knowledge of the current state of design theory, mathematics, and material behavior. To know these models is to both better understand the codes and to have methods to solve problems for which the code makes no recommendation.

3. Structural engineers are also responsible for participating in the process of excelling practice standards such as models and codes. As this paper stated before, this does not mean that every structural engineer should have a direct role in revolutionizing current standards of excellence. What it does mean is that all should use the current standards appropriately, where necessary note insufficiencies, and where possible contribute to their improvement.

4. It is the responsibility of structural engineers to articulate problems in the practice and work towards solving them. This responsibility applies to individual engineering projects such as buildings as well as to large scale research projects with broad impacts on the way engineering is done.

5. Structural engineers have a responsibility to understand and achieve the necessary outcomes of a project as expected by authorities such as clients, the law, and end users. These outcomes, or internal goods as we called them include strength, sustainability, safety, stability, and serviceability. 
There are other responsibilities mentioned in the previous section which are also applicable to structural engineering, although an extensive discussion of them lies outside the scope of this paper. The first responsibility regards what MacIntyre said about the life of a painter being an internal good of painting. Ethicists have noted that collective support and autonomy are important components of responsible behavior in the professions. These components require the support of cohesive community of engineers. Thus, we should consider what it means to live the life of an engineer and to be a part of a community of engineers. By taking these things to be internal goods, issues of collective support and professional autonomy can be placed as goals of engineering. The relevant responsibility for structural engineers can be stated thus:

6. Structural engineers are responsible for participating in a community of structural engineers which supports the profession as a whole.

There are a number of ways engineers can strengthen their community of engineering practitioners. Larry May mentions that professional engineering societies might perform this function (May 1996 p.117-122). Engineers can participate in conferences, publish papers in professional journals, mentor other engineers, and share their perspectives on their work and the work of their contemporaries. In cases such as whistle blowing, they can offer support to their colleagues.

The next and final responsibility has to do with what MacIntyre has said about putting our actions in narrative form so that ourselves and others can make proper sense of them. For engineers the relevant responsibility can be stated as:

7. Structural engineers have the responsibility to make an account of the relationship between their decision made in the course of their work and standards of excellence and goods of structural engineering. 
To make such an account, a structural engineer must be conscious of these elements, and any account given will serve as a narrative making the intentions of the engineer intelligible. One way this is commonly done in practice is by taking notes of research and design processes. Careful documentation of information and decision making is a responsibility which many engineers already fulfill. Engineers also write books and articles containing similar narratives of their work. Now, these actions have a philosophical basis that makes account making a responsibility. Though these accounts are not rightly available to anyone who might request them, they are important in a number of instances. In actions leading to legal disputes, a narrative of the intentions of structural engineers can be very important. Engineers who fulfill the responsibility to explain their work in terms of standards of excellence and goods also make a contribution to the previous responsibility to participate in the establishment of an engineering community. Their may be other instances where clients or victims of harm are entitled to such an account.

The responsibilities of structural engineers which this paper proposes have been derived from the concepts adopted from MacIntyre. They reflect an attempt to recognize a number of things structural engineers are responsible qua engineers. One benefit of looking at responsibility this way is that it is easy to see how the items on this list are interrelated. For instance, engineers who fulfill their responsibilities to achieve standards of excellence also achieve internal goods or desirable outcomes. Doing these things contributes to a fostering of community and the knowledge necessary to make a moral account of the engineers' own actions. Both of these outcomes are responsibilities in themselves. In the following section this paper provides a case study to better demonstrate how these responsibilities may or may not be fulfilled in actual practice. 


\section{THE SLEIPNER A CONDEEP PLATFORM ACCIDENT}

The failure and loss of the Sleipner A offshore platform in 1991 provides us with an opportunity to examine, in practice, the responsibilities we have previously ascribed to structural engineers. First, this case study incorporates the use of technical codes governing off-shore structures as well as the use of sophisticated structural analysis methods. Second, how the accident has been interpreted by engineers, investigators, and ethicists reveals the role and importance of narrative account making in engineering work. What follows is a brief description of the accident and a more detailed look at the facts of the situation as they pertain to the previously ascribed responsibilities of structural engineers.

The Sleipner A platform was a condeep, gravity base type offshore petroleum extraction platform. Condeep platforms are made of concrete and stand tall from the ocean floor to surface. They are used in the North Sea where conditions are harsh and petroleum may need to be stored within the platform structure during winter months (Wackers 2004; Michael Collins 1997). Gravity base structures (GBS's) are designed so that the weight of the concrete is enough to resist the upward force of ocean water displaced by the structure when it is lowered to the bottom of the ocean. The Sleipner A platform was of moderate size compared to other condeep platforms in operation (Michael Collins 1997; Wackers 2004). It consisted of 24 concrete-walled cylinders, less than 80 meters high, and bundled together to appear like a honeycomb in plan (Holand 1994; Michael Collins 1997). Each cylinder was 24 meters in diameter (Michael Collins 1997). It the interstices

of the cylinders triangular void spaces were created, called tricells (Wackers 2004). In order to raise and lower the platform in the ocean, water levels in the cylinders were controlled through mechanical-pump ballasting. Water levels in the tricells were not able to be controlled in such a way. On August 23, 1991, the Sleipner platform was towed to deep water for a ballasting test prior to being put into operation weeks later (Holand 1994; Michael Collins 1997; Wackers 2004). During submersion, a crash was heard and 
the platform began to sink. Roughly 18 minutes later the platform disappeared into the ocean causing a magnitude 3.0 earthquake near the coast of Norway as it hit the ocean floor. All workers on board were evacuated so that there was no loss of life.

Most accounts of the Sleipner accident emphasize the immediate causal and technical factors surrounding the loss of the platform. These accounts emphasis the fact that, once the pressure head difference between the water in the tricells and water in the cylinders reached roughly 65 meters, a crack developed between the two causing ballasting controls in the cylinders to fail. The strength of the walls between the two spaces was underestimated so that the walls could not withstand the loads caused by the pressure difference. Hypotheses of sinking scenarios, scale-tests, computer models, and full-scale model tests were all used during the post-accident investigation to conclude that a crack between tricell T23 and cylinder D3 caused the failure. ${ }^{1}$ There are two often cited reasons why the walls were insufficient. The first is that when finite element analysis was used to determine the required strength of the tricell wall, standard finite element modeling practices were not followed. Design engineers allowed a computer model that incorporated skewed finite elements when it was known that such elements can produce inaccurate results (Holand 1994). This led to a 43\% underestimation of the true shear strength required in the wall (Wackers 2004). At the same time, it was concluded that the proper size and placement of shear reinforcement, steel pieces known at T-bars, was insufficient. As this paper will claim, these two problems can be categorized as shortcomings in the areas of formal technical codes and abstract, analytical methods.

1 Two independent investigative agencies came to the same conclusion. One investigation was conducted by Norwegian Contractors, the company who was under contract to design and build the Sleipner A platform. The other investigation was conducted by SINTEF at the request of Statoil who owned the lease for the off-shore field where the Sleipner platform was to be operated. 
A few authors have written accounts of the accident which put the reasons the platform sank into the context of broader narratives. Collins et. al. have discussed the fact that concrete codes governing the design of off-shore concrete platforms in Norway were adopted from codes written by the American Concrete Institute (ACI) in the 1970s (Michael Collins 1997). According to the authors, it is known that these codes were insufficient for loading situations such as those which occurred in the tricell wall. The ACI code allowed for a reduction in shear reinforcement in concrete members subject to high compression loads. This allowance was a response to earlier structural failures where an opposite scenario occurred. Concrete members in tension were found to need more shear reinforcement than usual. The authors' point is that it is not always appropriate to assume that compression, the opposite of tension, reduces the need for shear reinforcement. Other concrete construction codes in use at the time, such as the AASHTO code, do not make similar allowances. The authors show through laboratory analysis that if the AASHTO code had been followed, the tricell wall would have likely held. Wackers has written an account that puts the failure of the platform into the context of the economic and corporate constraints imposed upon the project. At the time, petroleum prices were low and the contractor, Norwegian Contractors, was attempting for the first time to do all of required the engineering analysis in-house. So, the market was contracting at the same time the company was expanding its capabilities. In order to achieve profitability, engineers at Norwegian Contractors focused on saving material costs by optimizing the design, thus making the platform walls as thin and lightly reinforced as possible. The accounts of Collins et. al. and Wackers attempt to explain the failure of the Sleipner platform in terms which extend beyond the previously mentioned mistakes in finite element analysis and reinforcement placement.

Within these explanations of what caused the Sleipner platform to fail, there are issues related to the concepts which this paper has derived from MacIntyre's moral philosophy. First, this paper has previously claimed that formal codes and analytical methods are standards of excellence in the practice of engineering. Specifically, the codes for 
concrete construction which influenced the design of the Sleipner platform are candidates for scrutiny as codes of excellence in structural engineering. The method of finite element analysis for determining the stress on a structural object was, and is, one of the most advanced methods of analysis in structural engineering. Finite element analysis is a standard of excellence in current structural engineering practice. Second, the internal goods which this paper has previously recognized are central to the incident. Safety and strength are the most obvious goods in question. However, Wackers' account involves another good which complicates the others. This good is optimization. Finally, we can see in the various perspectives and conclusions reached by investigators such as Collins et. al., Holand, and Wackers, that a narrative account of why the platform failed helps us to reach conclusions about what the engineers intentions and mistakes were. Holand suggests that the finite element methods used by the engineers were vulnerable to miscalculation. Collins et. al. focus upon the codes governing the project as the source of problems. Wackers claims that the engineers did the very best they could possibly do and that the platform failed because of the external constraints imposed upon the design team by their company, their dedication to the ideal of optimization, and the economic conditions of the time. Recognizing these three points helps us to sort out the responsibilities of structural engineers qua structural engineers. In the remainder of this section, this paper will focus on these three issues as the bases for responsibilities in structural engineering.

In the terms ascribed by this paper, we can make a statement regarding what the engineers ought to have done or should do in similar situations. First there are those responsibilities which this paper has formed around knowledge and use of technical codes. Collins et. al have stated that the engineers at Norwegian Contractors followed the applicable Norwegian codes for concrete design. However, part of the failure of the Sleipner platform can be traced to the fact that the Norwegian codes were adopted from a version of the ACI code. The ACI code had a history of its own which led to its insufficiency under the particular circumstances in question, namely when a 
compression member is subjected to high shear forces. It is the responsibility of engineers to understand that codes are adopted for common problems as the American Institute of Steel Construction's Specification for Structural Steel Buildings states the "intention to provide design criteria for routine use and not to provide specific criteria for infrequently encountered problems, which occur in the full range of structural design (American Institute of Steel Construction. 2010 p.16.1-v)." It is also the responsibility of engineers to understand the source and history of technical codes. This brings us to our second responsibility. Structural engineers have the responsibility for understanding and working with the analytical models on which the codes are based. These models are also important for unusual instances where the codes are insufficient. Though engineers on the Sleipner platform design team did use the analytical methods of the time, finite element analysis, they failed to follow the finite element methods rigorously. The engineers used skewed shaped elements in their finite element model when standard practice recommended against this. This responsibility should have been higher prioritized because the Sleipner project was the first time Norwegian Contractors had conducted their own finite element analysis in-house (Wackers 2004). Though Wackers claims that the engineers on the project were doing the best job they could under the circumstances, this does not mean they were not responsible for the mistakes they made which led to the failure. Perhaps what it does mean is that when blame and liability were ascribed it was more appropriate to take action against the company, Norwegian Contractors, and not the individual engineers. Wackers' point that the economic and corporate circumstances in which the engineers worked made it difficult for them to behave otherwise is a good one. This paper takes the position that this makes them no less candidates for responsibility ascriptions as structural engineers. It does make them less likely candidates for blame and financial liability.

The Sleipner platform accident raises an interesting question about how structural engineers are responsible for internal goods or ends. In this instance, structural engineers were not able to ensure strength or safety. As Wackers points out, they were dedicated to 
the internal good of optimization. However, it is clear that optimization cannot be considered an outcome of a structural engineering project where strength and safety are not achieved. These facts raise three questions. First, if internal goods conflict in such a way are they really internal goods? Second, are there internal goods in structural engineering, such as strength, which are more important than others? Lastly, would structural engineering be what it is if strength was an internal good but optimization was not? This paper takes the position that structural engineers are responsible for more than adequate strength and this includes optimization, which is the same as efficiency which this paper previously established as a good. These questions need not be answered here in full, because it is part of responsible engineering practice to continuously pose and debate such questions.

The Sleipner case and the referenced investigative accounts into what caused the accident also highlight the responsibility engineers and engineering ethicists have to make accounts of their intentions, decisions, and actions. The investigations that took place after the accident were intently focused upon finding the source of the accident. The key reason this is so is because a new platform had to be built immediately. Despite this motivation, engineers at Norwegian Contractors, engineers in research groups at universities, engineers working for independent investigators, and engineering ethicists did work to produce narrative accounts which made the accident intelligible. To make an account of their actions is a responsibility of structural engineers, and in this case fulfillment of this responsibility had several positive consequences. First, the accounts made it possible to build a new platform. Second, the accounts serve to educate other engineers about their future actions. It is now easier to see the danger of skewed elements in finite element analysis. It is also easier to grasp the shortcomings of certain concrete codes governing the design process. Making these points explicit contributes to the responsibility structural engineers have to expose problems and seek solutions to those problems. All of these outcomes contribute to the evolution of what constitutes excellence in structural engineering. When practitioners fulfill these responsibilities, 
they are furthering the standards of excellence and internal goods of their practice in the manner discussed by MacIntyre.

The Sleipner platform accident provides us with an opportunity to establish what the structural engineers on the project should have done but more importantly, what structural engineers should be doing in current practice. Engineers must understand and follow the technical codes of their practice. In addition, they must know the limitations of those codes and more importantly, the theories of engineering which supplement and underlie the codes. Engineers are responsible for achieving the internal goods of their practice. This is done by fulfilling their responsibilities to technical codes and analytical methods. Making accounts of their intentions and decisions is a responsibility which allows others to judge how the other responsibilities have been fulfilled. All of these responsibilities are integral to what engineers do, that is identify and solve material problems. 


\section{CONCLUSION}

This paper has ascribed the responsibilities of engineers, particularly structural engineers, by considering engineering as a practice with its own standards of excellence and internal goods. In the process, the focus has been on the responsibilities engineers have qua engineers. The concepts we have adopted from Alasdair MacIntyre's moral philosophy have been used to identify what engineers ought to do. These concepts include practices, standards of excellence, internal goods, traditions, narrative, and intelligibility. This paper has derived from the relationship between these concepts a list of responsibilities engineers have qua engineers. These responsibilities have been applied to the specific practice of structural engineering.

First, the concept of a practice is central to this paper's objective of identifying the specific responsibilities of engineers, but it is equally as important to the philosophy of MacIntyre. MacIntyre identifies practices as important for moral philosophy because practices have existed throughout time and across cultures that preceded individual moral philosophies. According to MacIntyre, the social interactions which make practices are more fundamental than the changing rationalities of moral philosophy. This paper established engineering as a practice as a starting point for determining what engineers should be responsible for simply as engineers so that any debate regarding those responsibilities is a debate about engineering and not philosophy.

MacIntyre's definition of practices includes the concepts of standards of excellence and internal goods. These two concepts are the basis of what engineers are responsible for. This paper has identified technical codes, analytical methods, and abstract models as standards of engineering practice which do represent excellence in the practice. It is important for engineers to maintain these standards as excellences by continually working to know them thoroughly, successfully implement them in practice, identify short-comings of the standards, and improve upon them. This paper also proposed that a 
number of outcomes of engineering work are internal goods of the practice. In structural engineering these goods are strength, serviceability, stability, safety, and efficiency. The case of the Sleipner A platform accident raised the question of how these goods should be ordered and prioritized. These questions may remain unanswered here for it is the job of practitioners to debate their function and importance to the practice. This is how practices excel. What is important is that structural engineers remain conscious of the relationship between standards of excellence and internal goods during the course of their work.

The additional concepts of traditions, narrativity and intelligibility help us to further articulate the responsibilities of engineers. This paper has said that knowledge of the tradition of which one is a part aids responsible behavior. Practitioners inherit responsibilities from the people which have gone before them in the history of the practice. They also inherit problems to solve. This process leads to the furthering of standards and goods. Narrativity helps us to put the decisions and intentions of practitioners into a context which makes sense of those actions. Though this is a paper solely on responsibilities, the ability to identify the intentions and decisions of practitioners is useful for deciding how to attribute blame and liability.

During the course of this analysis, this paper has avoided making distinctions between harm and benefit of society and technical and social responsibilities. These matters are not so simple. However, issues of harm and benefit on the part of engineers can be addressed by understanding the it is the responsibility of engineers to pursue and achieve excellence in engineering. When this is done, engineers have fulfilled their obligations to society. It is apparent that if technical standards of excellence are followed with the intent of achieving internal goods then both social and technical obligations can be met. Just as the achievement of internal goods in $18^{\text {th }}$ century European portraiture enriched the history of art, the achievement of internal goods in engineering leads to outcomes which better society. One final point is that the responsible behavior of engineers is not 
only good for engineering but is necessary for achieving and advancing the greater good for society. 


\section{REFERENCES}

American Institute of Steel Construction. (2010). Specification for Structural Steel Buildings. In Steel Construction Manual (14th ed.). Chicago, IL: American Institute of Steel Construction.

Bowen, W. R. (2010). Prioritising people: outline of an aspirational engineering ethic. In D. E. Goldberg \& I. van der Poel, (Eds.), Philosophy and Engineering: (Vol. 2, pp. 135-146, Philosophy of Engineering and Technology). Netherlands: Springer.

Badaracco Jr., J. \& Webb, A. (1995). Business ethics: a view from the trenches. California Management Review, 3, 8-28.

Busby, J., \& Coeckelbergh, M. (2003). The social ascription of obligations to engineers. Science and Engineering Ethics, 9(3), 363-376, doi:10.1007/s11948-003-0033-X.

Collins, M., Gupta, P., \& Selby, R., (1997). The failure of an offshore platform. Concrete International, 19(8), 28-35.

Davis, M. (1997). Is there a profession of engineering? Science and Engineering Ethics, 3(4), 407-428, doi:10.1007/s11948-997-0044-0.

Davis, M. (2010). “Ain’t no one here but us social forces": constructing the professional responsibility of engineers. Science and Engineering Ethics, 18(1), 13-34, doi:10.1007/s11948-010-9225-3.

Davis, M. (2011). A plea for judgment. Science and Engineering Ethics, Online First, doi:10.1007/s11948-011-9254-6.

Doorn, N. (2009). Responsibility ascriptions in technology development and engineering: three perspectives. Science and Engineering Ethics, 18(1), 69-90, doi:10.1007/s11948-009-9189-3.

Doorn, N., \& Nihlén-Fahlquist, J. (2010). Responsibility in engineering: toward a new role for engineering ethicists. Bulletin of Science, Technology \& Society, 30(3), 222-230, doi:10.1177/0270467610372112.

Fischer, J. M., \& Tognazzini, N. A. (2011). The physiognomy of responsibility. Philosophy \& Phenomenological Research, 82(2), 381-417. 
Fleddermann, C. (1999). The rights and responsibilities of engineers. In C. Fledderman, Engineering Ethics (pp. 79-100). Upper Saddle River, NJ: Prentice Hall.

Harris, C. E. (2008). The good engineer: giving virtue its due in engineering ethics. Science and Engineering Ethics, 14(2), 153-164.

Holand, I. (1994). The Loss of the Sleipner Condeep Platform. Paper presented at the Diana Conference on Computational Mechanics. Delft, Netherlands.

Johnson, D. (1992). Do engineers have social responsibilities? Journal of Applied Philosophy, 9(2), 21-34.

Layton, E. T. (1971). The Revolt of the Engineers; Social Responsibility and the American Engineering Profession. Cleveland, OH: Press of Case Western Reserve University.

MacIntyre, A. C. (1984a). After Virtue : A Study in Moral Theory (2nd ed.). Notre Dame, IN.: University of Notre Dame Press.

MacIntyre, A. C. (1984b). Bernstein's distorting mirrors: a rejoinder. Soundings, 37, 3041.

Martin, M. W. (2002). Personal meaning and ethics in engineering. Science and Engineering Ethics, 8(4), 545-560.

May, L. (1996). The Socially Responsive Self: Social Theory and Professional Ethics. Chicago, IL: University of Chicago Press.

Mead, D. W. (1980). Why a code of conduct? In B. Flores (Ed.), Ehtical Problems in Engineering. Troy, NY: Center for the Study of the Human Dimensions of Science and Technology.

Mitcham, C. (1994). Engineering design research and social responsibility. In K. S. Shrader-Frechette (Ed.), Ethics of Scientific Research (pp. x, 243 p., Issues in Academic Ethics). Lanham, MD: Rowman \& Littlefield.

Nichols, S., \& Weldon, W. (1997). Professional responsibility: the role of the engineer in society. Science and Engineering Ethics, 3(3), 327-337, doi:10.1007/s11948997-0039-x. 
Nissenbaum, H. (2002). New research norms for a new medium. In N. E.-K. Netanel (Ed.), The Commodification of Information. (pp. pp. 433-457). The Hague: Kluwer Academic Press.

NSPE (2007). Code of Ethics for Engineers. (pp. 2).

http://www.nspe.org/Ethics/CodeofEthics/index.html: National Society of Professional Engineers.

Pielke, R. A. (2007). The Honest Broker: Making Sense of Science in Policy and Politics. Cambridge, UK: Cambridge University Press.

Pritchard, M. S. (1998). Professional responsibility: focusing on the exemplary. Science and Engineering Ethics, 4(2), 215-233.

Pritchard, M. S. (2001). "Doing the minimum". Science and Engineering Ethics, 7(2), 284-285.

Randolph, D. (1992). Civil engineers shaping society: our social responsibilities. Journal of Professional Issues in Engineering Education and Practice, 118(1), 10-15.

Smith, A. (2007). On being responsible and holding responsible. The Journal of Ethics, 11(4), 465-484, doi:10.1007/s10892-005-7989-5.

Stieb, J. A. (2011). Understanding engineering professionalism: a reflection on the rights of engineers. Science and Engineering Ethics, 17(1), 149-169, doi:10.1007/S11948-009-9166-X.

Timoshenko, S. (1983). History of Strength of Materials. New York City, NY: Dover Publications, Inc.

Unger, S. H. (1994). Controlling Technology: Ethics and the Responsible Engineer. (2nd ed.). New York City, NY: John Wiley \& Sons.

van der Burg, S., \& van Gorp, A. (2005). Understanding moral responsibility in the design of trailers. Science and Engineering Ethics, 11(2), 235-256.

Wackers, G. (2004). Resonating Cultures: Engineering Optimization in the Design and ( 1991) Loss of the Sleipner A GBS. Working paper. Maastricht, Netherlands: University of Maastricht.

Watson, G. (1996). Two faces of responsibility. Philosophical Topics, 24(2), 227-248. 
Wells, M. (2010). Engineers: A History of Engineering and Structural Design. New York City, NY: Routledge. 